\title{
Does the Age Profile of Health Care Expenditure Really Steepen over Time? New Evidence from Swiss Cantons
}

\author{
Stefan Felder ${ }^{\mathrm{a}}$ and Andreas Werblow ${ }^{\mathrm{b}}$ \\ ${ }^{a}$ Health Economics, Duisberg-Essen University, 45117 Essen, Germany. \\ E-mail: stefan.felder@uni-due.de \\ ${ }^{\mathrm{b}}$ Department of Economics, TU Dresden, Dresden 01062, Germany. \\ E-mail: Andreas.Werblow@tu-dresden.de
}

Buchner and Wasem (2006) claimed that the health care expenditure (HCE) of the old grows faster than that of the young, resulting in a steepening of the age profile of HCE over time. This paper tests the steepening claim for Swiss health insurance, covering the time period 1997-2006 and the 26 cantons. It analyses the cantonal HCE profile of men and women, taking into account differences in the mortality rates. The study covers seven components of health care, including long-term care. By and large, no evidence is found for relevant higher growth rates for either total or the components of HCE in old age.

The Geneva Papers (2008) 33, 710-727. doi:10.1057/gpp.2008.28

Keywords: ageing; health care expenditure; end-of-life expenditure

\section{Introduction}

A growing body of evidence suggests that the higher health care expenditure (HCE) incurred by older people may be caused by proximity to death rather than calendar age. Consequently, projections not accounting for proximity to death are likely to overstate the effect of population ageing on future HCE. Evidence for the "age neutrality" or "red herring" hypothesis often rests on the analysis of cross-sectional data. Sceptics thus point to longitudinal data in the hope of re-establishing the old "age matters" hypothesis.

In a recent paper, Buchner and Wasem $^{1}$ found for the largest German private health insurer that high-cost older age groups had larger increases in HCE than the young and middle-aged groups in the period from 1979 to 1996. Organisation for Economic Cooperation and Development HCE data on the time trends in per capita expenditure for the 65 -and-older age group vs. the under-65 age group show a similar pattern. ${ }^{2}$ Buchner and Wasem introduced the term "steepening" of the health expenditure profile to characterise the effects of age and time on HCE. If steepening can be assumed to prevail, they claim that "the future increase of health care costs will even be larger than in predictions that keep expenditure profiles

\footnotetext{
${ }^{1}$ See Buchner and Wasem (2006).

${ }^{2}$ See Seshamani and Gray (2002).
} 
constant." 3 This quote echoes the catastrophic scenarios on future HCE that were in vogue in the 1990s. For example, Schneider and Guralnik ${ }^{4}$ expect HCE for older people to double by 2020 largely due to the ageing of the baby boom generation.

Several factors can influence the age profile of per capita HCE. The profile will steepen if the expansion of the technological frontier in medicine is biased towards the treatment of old age diseases. On the other hand, there are several factors that will work in the opposite direction. Firstly, if compression of morbidity takes place and the average health status in old age improves with the passage of time, average HCE in old age decreases. ${ }^{5}$ Secondly, greater longevity, which pushes death later in life, will also lower per capita HCE due to the level and the age profile of the end-of-life expenditure. The high cost of dying reduces average HCE when the mortality rate decreases. The reduction of mortality pertinent to all ages, but accentuated in old age, will therefore reduce the age gradient of HCE in old age. Research also shows that those who die at older ages have lower health care costs than those who die at younger ages. Per capita HCE in old age thus will decrease with the deferral of death to ever higher ages.

This paper tests the steepening claim using longitudinal HCE data of social health insurance for the years 1997-2006 in the 26 Swiss cantons. These data distinguish between women and men as well as between 20 five-year age groups. The full sample contains $10 \times 26 \times 20 \times 2=10,400$ observations. Aggregate HCE can be decomposed into seven components, including ambulatory care (AC), prescription drugs, hospital inpatient and outpatient care, home care (HC), nursing home care (NHC) and other services. Furthermore, these data include age-, sex- and regional-specific mortality rates. Therefore, we can analyse the interdependence between mortality and age in their impact on HCE.

This paper is organised as follows. The following section presents the data and a first glimpse of steepening. The next section characterises steepening based on age-specific growth rates of HCE over time. The subsequent section describes the econometric approach and presents the results regarding steepening of aggregated HCE data. The penultimate section deals with the components of HCE. The final section concludes.

\section{A first look at the data}

This study is based on age profiles of aggregate HCE and mortality rates in the 26 Swiss cantons for the 10 years from 1997 to 2006. HCE data stem from the association of the Swiss social health insurers and mortality rates data come from the Federal Office of Statistics. The social health insurance expenditure data distinguish 20 fiveyear age groups of health care spending for men and women, starting at ages $0-5,6-10$ and ending at ages 96 and older. These data are available for each canton. The health insurers pay for cross-cantonal-border demand by their insured; hence, HCE are

\footnotetext{
${ }^{3}$ Buchner and Wasem (2006, p. 582).

${ }^{4}$ Schneider and Guralnik (1990).

${ }^{5}$ Fries $(1980,2005)$.
} 
correctly assigned to the origin of demand. Using the producer price index (GDP deflator), we express all HCE in 2006 SFr. Cantonal mortality rates for men and women are also available in 20 five-year age groups for the years 1997-2006.

Switzerland introduced compulsory basic health insurance in 1996. Basic health insurance can be offered by any insurer and covers a widely defined set of medical services. The insured has free choice between all insurers offering contracts in his canton of residence. Community rating applies on a regional level. Regional risk adjustment schemes correct for differences in the age and sex composition of the insurers' risk pools. Basic health insurance finances about 43 per cent of total HCE. Half of hospital costs are financed through cantonal tax revenues giving rise to a total of 60 per cent of public expenditure. The remaining 40 per cent includes out-of-pocket payments or private extra insurance. ${ }^{6}$ Recent legislation has hardly changed basic social insurance. Since 2001, coverage of long-term care has been extended and insurers have started to rearrange their contracts with long-term care providers. As we will study components of health care we should be able to detect possible impacts of policy changes on the age profile of HCE.

More expensive treatment costs imply a higher remuneration of health care providers in all sectors of health care and thus result in higher per capita HCE in the respective age group. For this reason, these data appear to be suitable to reflect possible steepening of HCE profiles.

In 2006, the per capita HCE in social health insurance was 2,759 SFr. In 1997, HCE in social health insurance was $1,928 \mathrm{SFr}$. The average annual real growth rate amounted to 4.3 per cent over the 10 -year period. The average $\mathrm{HCE}$ of a woman was higher than that of a man by a factor of 1.35 (in 2006 3,163 SFr. as against 2,338 SFr.). The age profiles for women and men are relatively flat at young ages with a small gradient beyond age 20. Sixty-year-olds incur on average 3,398 SFr. for health care. This amount doubles by the age of 80 and reaches 16,919 SFr. for men of aged $95+$ and 20,711 SFr. for women of the same age.

Figure 1 shows the average age profile of per capita HCE in Swiss cantons at the beginning and the end of the study interval. For the very old, that is people older than 80 years, the age profile seems to have become flatter between 1997 and 2006. Hence, steepening appears not to be present for the very old. By comparison, some steepening in absolute terms might be occurring for the ages 60-80. Steepening in relative terms, that is a higher growth rate of HCE for these ages, seems not to be present.

Table 1 presents two ratios of per capita HCE between the old and the young for 25 Swiss cantons (we aggregated the small two semi-cantons of Appenzell into one canton). For the country as a whole, per capita spending in 2006 for ages 66 and over was four times higher than that for ages 0-65. In 1997, this ratio equaled 3.85, which was 3.93 per cent lower than that in 2006. In the cantons, the $66+/ 0-65$ ratio of per capita HCE ranged between 3.62 and 4.60 in 2006, and between 3.50 and 4.93 in 1997. Hence, between 1997 and 2006, the range became smaller. The increase in the ratio ranges between -9.68 and 14.54 per cent. In 10 out of 25 cantons, the ratio decreased

\footnotetext{
${ }^{6}$ See OECD (2007).
} 


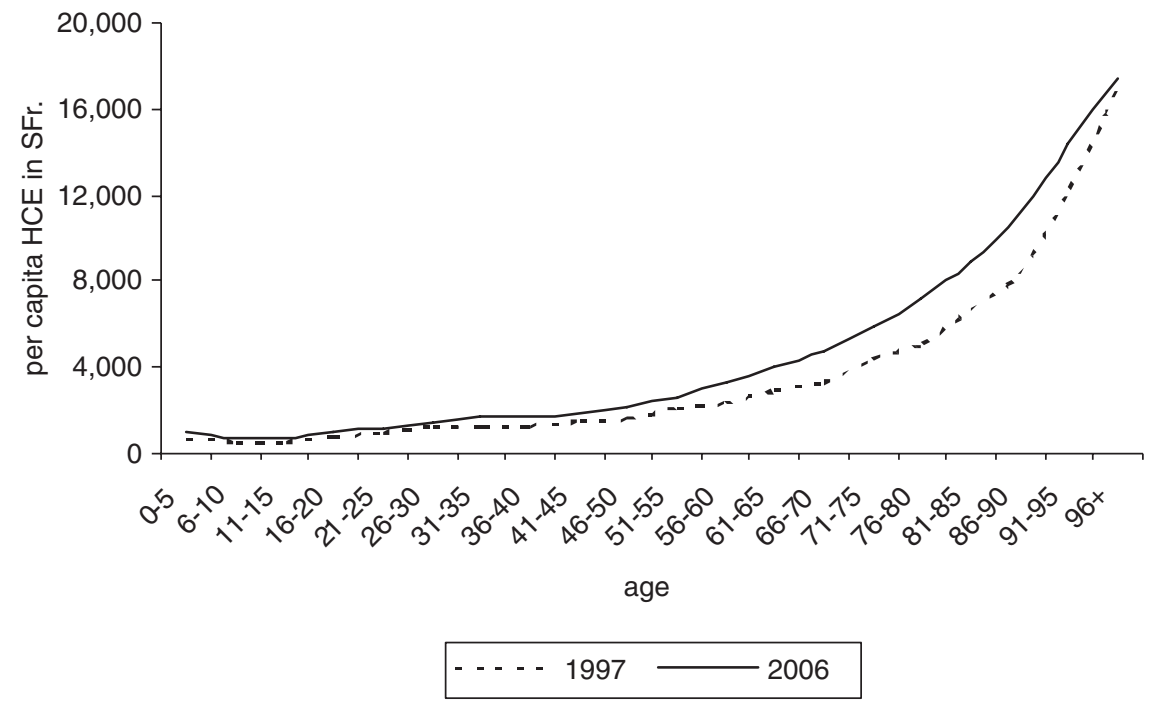

Figure 1. The change in the age profile of per capita HCE in Switzerland, 1997-2006.

Table 1 The ratio of per capita HCE between the old and the young generations

\begin{tabular}{|c|c|c|c|c|c|c|}
\hline & \multicolumn{3}{|c|}{ Ratio of $66+$ to $0-65$} & \multicolumn{3}{|c|}{ Ratio of $51+$ to $0-50$} \\
\hline & 1997 & 2006 & Relative change (\%) & 1997 & 2006 & Relative change (\%) \\
\hline Aargau & 3.92 & 3.87 & -1.36 & 3.49 & 3.49 & -0.06 \\
\hline Appenzell & 3.78 & 3.92 & 3.67 & 3.59 & 3.72 & 3.57 \\
\hline Baselland & 3.59 & 3.62 & 0.90 & 3.12 & 3.26 & 4.75 \\
\hline Basel-Stadt & 3.50 & 3.73 & 6.59 & 3.28 & 3.67 & 11.83 \\
\hline Bern & 4.04 & 3.98 & -1.43 & 3.62 & 3.78 & 4.38 \\
\hline Fribourg & 4.25 & 4.09 & -3.93 & 3.63 & 3.64 & 0.37 \\
\hline Genève & 3.70 & 3.91 & 5.49 & 3.04 & 3.34 & 9.67 \\
\hline Glarus & 3.94 & 3.68 & -6.48 & 3.63 & 3.28 & -9.56 \\
\hline Graubünden & 3.69 & 4.14 & 12.16 & 3.51 & 3.81 & 8.60 \\
\hline Jura & 4.93 & 4.45 & -9.68 & 4.26 & 4.15 & -2.56 \\
\hline Luzern & 4.19 & 4.49 & 7.04 & 3.85 & 4.04 & 5.05 \\
\hline Neuchâtel & 4.07 & 4.17 & 2.52 & 3.54 & 3.96 & 11.77 \\
\hline Nidwalden & 4.05 & 3.93 & -2.92 & 3.60 & 3.51 & -2.35 \\
\hline Obwalden & 4.53 & 4.40 & -2.94 & 3.93 & 3.91 & -0.61 \\
\hline Schaffhausen & 3.89 & 3.83 & -1.72 & 3.67 & 3.61 & -1.77 \\
\hline Schwyz & 4.34 & 4.15 & -4.38 & 3.73 & 3.59 & -3.83 \\
\hline Solothurn & 3.88 & 3.90 & 0.69 & 3.52 & 3.63 & 2.97 \\
\hline St. Gallen & 3.78 & 3.85 & 1.70 & 3.44 & 3.53 & 2.51 \\
\hline Ticino & 3.60 & 4.03 & 11.94 & 3.34 & 3.97 & 18.98 \\
\hline Thurgau & 3.98 & 3.98 & -0.10 & 3.54 & 3.55 & 0.26 \\
\hline Uri & 4.30 & 4.60 & 7.01 & 4.20 & 4.26 & 1.55 \\
\hline Vaud & 3.62 & 4.15 & 14.54 & 3.17 & 3.71 & 17.16 \\
\hline Valais & 4.05 & 4.14 & 2.00 & 3.78 & 3.81 & 0.75 \\
\hline Zug & 4.00 & 4.09 & 2.39 & 3.33 & 3.55 & 6.84 \\
\hline Zürich & 3.66 & 3.86 & 5.46 & 3.13 & 3.37 & 7.65 \\
\hline Switzerland & 3.85 & 4.00 & 3.93 & 3.42 & 3.62 & 6.01 \\
\hline
\end{tabular}


The Geneva Papers on Risk and Insurance - Issues and Practice 714

Table 2 Population, per capita total and components of health care expenditure in Swiss cantons

\begin{tabular}{|c|c|c|c|c|c|c|c|c|c|c|c|}
\hline \multicolumn{2}{|l|}{ Canton } & \multirow{2}{*}{$\begin{array}{l}\text { Population } \\
\text { (in 100,000) }\end{array}$} & \multicolumn{2}{|c|}{$H C E$} & \multicolumn{7}{|c|}{ Components of $H C E$} \\
\hline Name & No. & & Men & Women & $A C$ & Drugs & $H I P$ & $H O P$ & $H C$ & $\mathrm{NHC}$ & Other \\
\hline Nidwalden & 13 & 0.39 & 1,724 & 2,366 & 443 & 407 & 478 & 321 & 42 & 147 & 204 \\
\hline Obwalden & 14 & 0.33 & 1,779 & 2,478 & 438 & 412 & 469 & 404 & 41 & 173 & 191 \\
\hline Appenzell & 2 & 0.66 & 1,780 & 2,325 & 478 & 385 & 514 & 316 & 33 & 181 & 145 \\
\hline Zug & 24 & 1.05 & 1,855 & 2,642 & 556 & 414 & 533 & 323 & 24 & 193 & 203 \\
\hline Uri & 21 & 0.35 & 1,894 & 2,525 & 466 & 414 & 585 & 351 & 45 & 208 & 140 \\
\hline Luzern & 11 & 3.57 & 1,925 & 2,588 & 486 & 442 & 553 & 340 & 36 & 221 & 183 \\
\hline St. Gallen & 18 & 4.50 & 1,944 & 2,591 & 573 & 469 & 547 & 287 & 35 & 185 & 175 \\
\hline Schwyz & 16 & 1.36 & 1,972 & 2,658 & 577 & 452 & 548 & 311 & 33 & 195 & 196 \\
\hline Graubünden & 9 & 1.89 & 1,975 & 2,710 & 549 & 506 & 545 & 312 & 48 & 185 & 200 \\
\hline Glarus & 8 & 0.37 & 1,995 & 2,673 & 554 & 478 & 509 & 335 & 32 & 228 & 200 \\
\hline Thurgau & 20 & 2.30 & 2,004 & 2,641 & 498 & 407 & 670 & 338 & 35 & 185 & 191 \\
\hline Schaffhausen & 15 & 0.72 & 2,119 & 3,064 & 578 & 565 & 573 & 408 & 42 & 236 & 205 \\
\hline Wallis & 23 & 2.97 & 2,135 & 2,780 & 527 & 572 & 604 & 324 & 41 & 172 & 222 \\
\hline Aargau & 1 & 5.58 & 2,149 & 2,819 & 546 & 546 & 650 & 372 & 34 & 148 & 189 \\
\hline Fribourg & 6 & 2.54 & 2,200 & 2,990 & 584 & 564 & 621 & 329 & 40 & 236 & 225 \\
\hline Zürich & 25 & 12.44 & 2,260 & 3,116 & 720 & 530 & 601 & 353 & 46 & 238 & 208 \\
\hline Solothurn & 17 & 2.41 & 2,319 & 2,988 & 595 & 561 & 656 & 401 & 63 & 150 & 231 \\
\hline Jura & 10 & 0.64 & 2,411 & 3,114 & 504 & 648 & 723 & 441 & 92 & 173 & 186 \\
\hline Neuchâtel & 12 & 1.68 & 2,451 & 3,465 & 567 & 734 & 624 & 338 & 86 & 361 & 264 \\
\hline Baselland & 3 & 2.58 & 2,471 & 3,187 & 732 & 569 & 706 & 420 & 51 & 126 & 232 \\
\hline Bern & 5 & 9.18 & 2,552 & 3,381 & 584 & 568 & 829 & 435 & 69 & 280 & 214 \\
\hline Vaud & 22 & 6.36 & 2,670 & 3,671 & 690 & 691 & 644 & 585 & 101 & 213 & 264 \\
\hline Ticino & 19 & 3.12 & 2,878 & 3,667 & 688 & 723 & 867 & 397 & 56 & 255 & 303 \\
\hline Genève & 7 & 4.03 & 3,008 & 4,287 & 989 & 797 & 762 & 494 & 72 & 215 & 342 \\
\hline Basel-Stadt & 4 & 1.76 & 3,024 & 4,151 & 739 & 766 & 987 & 545 & 85 & 245 & 251 \\
\hline Switzerland & & 72.79 & 2,338 & 3,163 & 634 & 571 & 665 & 394 & 55 & 216 & 223 \\
\hline
\end{tabular}

indicating an absence of steepening, whereas in 15 cantons the ratio increased pointing to possible steepening effects.

The second ratio compares ages 51 and older with ages 50 and younger. Not surprisingly this ratio is lower than the $66+/ 0-65$ ratio. Interestingly, however, the change in the $51+/ 0-50$ ratio from 1997 to 2006 is much higher (6.01 per cent as opposed to 3.93 per cent). The change ranges from -9.56 to 18.98 per cent and is negative in six cantons only. The difference between the two indicators points to a marked increase in per capita HCE for the ages 51-65. In econometrics, by using the ages $0-50$ as the benchmark, we will apply a sharper test for the occurrence of steepening.

The HCE data distinguish several components of acute and long-term care. Acute HCE include AC, hospital outpatient care (HOP), hospital inpatient care (HIP), prescription drugs and other services. Long-term care has two components, NHC and HC. Table 2 shows HCE and its components across 25 Swiss cantons. 
Table 3 The ratio of per capita HCE between the old and the young generations - components of health care

\begin{tabular}{lrrrrrrr}
\hline Components & \multicolumn{3}{c}{ Ratio of 66+ to 0-65 } & & \multicolumn{3}{c}{ Ratio of 51+ to 0-50 } \\
\cline { 2 - 3 } \cline { 7 - 8 } & 1997 & 2006 & Relative change (\%) & & 1997 & 2006 & Relative change (\%) \\
\hline Ambulatory care & 2.03 & 2.29 & 12.93 & & 2.01 & 2.24 & 11.36 \\
Drugs & 3.83 & 3.86 & 0.70 & & 4.33 & 4.35 & 0.41 \\
Hospital inpatient care & 5.28 & 4.66 & -11.71 & & 4.51 & 4.17 & -7.51 \\
Hospital outpatient care & 2.43 & 2.48 & 2.28 & & 2.43 & 2.61 & 7.46 \\
Home care & 31.02 & 28.79 & -7.18 & & 28.79 & 31.75 & 10.29 \\
Nursing home care & 59.25 & 81.41 & 37.39 & & 54.38 & 111.41 & 104.89 \\
Other & 2.41 & 2.20 & -8.96 & & 2.29 & 2.16 & -5.56 \\
\hline
\end{tabular}

The table is sorted according to the average HCE of men. Cantons in the centre of Switzerland show the lowest per capita HCE followed by cantons in the east. NonGerman speaking cantons incur the highest per capita HCE. Total hospital care (HOP and HIP) makes up 40 per cent of total HCE, AC 25 per cent, drugs 20 per cent, followed by long-term care and other services, which both have a share of roughly 10 per cent.

Table 3 shows the $66+/ 0-65$ ratio and the $51+/ 0-50$ ratio of per capita HCE between the old and the young for the components of health care at the federal level. For the use of prescription drugs, we observe no relative change between 1997 and 2006 for both ratios. The changes are negative for HIP as well as for other services (other). Thus, there is no indication of steepening in these three components of health care. However, in AC, HOP and the two components of long-term care ( $\mathrm{HC}$ and $\mathrm{NHC})$, the increase in the ratios is substantial, in particular for NHC.

We observe large differences between the two ratios for long-term care. When we compare the 66 and older age group with the 0-65 age group, the ratio for $\mathrm{HC}$ decreased by 7.18 per cent, whereas for NHC it increased by 37.39 per cent between 1997 and 2006. By comparison, when we cut at age 51, the ratios increased by 10.29 per cent and as much as 104.89 per cent, respectively. These differences point to significant changes in long-term care for ages 51-65 relative to the other age groups.

In the 10-year time period analysed here, the reduction of mortality led to an average increase in the Swiss population's longevity of 2.2 years (from 79.30 years in 1997 to 81.50 years in 2006). As HCE in the last year of life is about 5-10 times higher than the average HCE of survivors, ${ }^{7}$ the general accentuated reduction of the mortality rate in old age will most likely affect the HCE age profile of the elderly. Thus, it is important to consider the influence of mortality when testing for a possible steepening of the age profile.

\footnotetext{
${ }^{7}$ Zweifel et al. (1999).
} 


\section{Identifying steepening of the HCE age profile}

Our analysis of steepening starts from a simple growth model that assumes that total per capita HCE increases by a factor $g$ over time $t:^{8}$

$$
h_{t}=h_{0}(1+g)^{t},
$$

where $h_{0}$ is the starting value of HCE. Taking the logarithm yields

$$
\ln h_{t}=\ln h_{0}+t \ln (1+g) \text {. }
$$

This growth path is influenced by other factors, some of which can be observed and others cannot. For instance, mortality is observable while morbidity is not. Then the more general model is

$$
\begin{aligned}
\ln h_{t} & =\ln h_{0}+t \ln (1+g)+\delta m_{t} \\
& =\alpha+\beta t+\delta m_{t},
\end{aligned}
$$

where $\alpha=\ln h_{0}$ and $\beta=\ln (1+g){ }^{9}$ Finally, to address possible steepening, we render the growth rate to be dependent on age and assume that $\beta_{a}=\beta+\gamma_{a} a=\ln \left(1+g+g_{a}\right)$, giving rise to

$$
\ln h_{a, t}=\alpha_{a}+\left(\beta+\gamma_{a} a\right) t+\delta m_{a, t} .
$$

In this equation, $\gamma_{a}$ measures the age-specific differences to the constant HCE growth rate $\beta . \gamma_{a}$ will be decisive for determining possible steepening. If $\gamma_{a}>0$, steepening may be present. Note, however, that since the mortality rate is also changing in time and age, this in turn will also have an effect on the evaluation of a possible steepening.

Steepening in the strict sense of the word means that the growth rate of HCE rises with an increasing age. Steepening thus is present if the mixed derivative of $\ln h_{a, t}$ with respect to age and time is positive:

$$
\frac{\partial^{2} \ln h_{a, t}}{\partial a \partial t}=\gamma_{a}+\delta \frac{\partial^{2} m_{a, t}}{\partial a \partial t}>0
$$

Given the high end-of-life expenditure, HCE is assumed to rise with an increase in the mortality rate, that is $\delta>0$. The compression of mortality to ever higher ages is a well-known secular trend. ${ }^{10}$ Technically this means that $\partial^{2} m_{a, t} /(\partial a \partial t)<0$. With $\delta>0$, the second summand in (5) then is negative. This implies that $\gamma_{a}>0$ is a necessary but not sufficient condition for steepening to be present.

Buchner and Wasem ${ }^{11}$ proposed three alternative methods for detecting steepening. The first compares per capita HCE between people of age 65 and older, and people under-65 years of age:

$$
\frac{\bar{h}_{65+, t}}{\bar{h}_{0-64, t}}=\sigma t \frac{\bar{h}_{65+, 0}}{\bar{h}_{0-64,0}} \quad \text { with steepening if } \quad \sigma>0 .
$$

\footnotetext{
${ }^{8}$ This is a standard model in the econometrics of time series HCE data (see Barros (1998) and more recently Hartwig (2008)).

${ }^{9}$ This is called a semilog model (see Gujarati, 2000).

${ }^{10}$ Fries (2005) and Cheung and Robine (2007).

${ }^{11}$ Buchner and Wasem (2006).
} 
As far as steepening is concerned, this boils down to a model with two age groups only, the young and the old. Consequently, $\sigma>0$ is a very crude indicator of steepening.

The second approach assumes a linear trend over time for HCE at each age:

$$
\begin{array}{r}
\frac{h_{a, t}}{h_{0, t}}=\mu+\kappa_{a} t \quad \text { with steepening if } \\
\kappa_{a}>0 \text { and } \frac{\partial \kappa_{a}}{\partial a}>0 .
\end{array}
$$

Two problems arise with this specification. Firstly, empirical evidence suggests that growth of per capita HCE is exponential not linear in time. Secondly, (7) does not allow for age-specific constants again contradicting empirical fact.

The third alternative assumes that the health care profile is exponential in age according to:

$$
\begin{gathered}
\frac{h_{a, t}}{h_{0, t}}=\tau+\exp \left(v_{t} a\right) \quad \text { with steepening if } \\
v_{t}>0 \quad \text { and } \quad \frac{\partial v_{t}}{\partial t}>0 .
\end{gathered}
$$

Again, this specification appears to be too restrictive.

Buchner and Wasem ${ }^{12}$ were bound to inflexible functional forms as they had access to HCE time series of 18 years only. By comparison, the large data set of the present study with 25 regions allows us to model the HCE age profile quite flexibly and to take into account time and mortality rates. We will also run regressions where we do not include the mortality rate as an explanatory variable. Although this yields biased coefficient estimates (the error term is correlated with the explanatory variables age and time, as they also determine mortality), we can gain some additional information on steepening by comparing the corresponding coefficients for regressions with and without the mortality rates, as well as on the influence of mortality on the HCE age profile.

We will analyse the change of the age gradient for the age groups older than 50 . A less strict test for steepening is the relative growth of HCE for ages 51 and older compared to ages $0-50$. We will report on further approaches to testing for steepening of the HCE age profile.

\section{Analysis of total HCE}

For the econometric analysis, we extend the equation by including additional variables for gender, canton and a disturbance term:

$$
\begin{aligned}
\ln h_{a, t, r}= & \alpha_{1,0,1}+\theta d_{\text {sex }}+\sum_{r=2}^{25} \kappa_{r} d_{r}+\sum_{a=2}^{20} \mu_{a} d_{a} \\
& +\beta t+\sum_{a=11}^{20} \gamma_{a} d_{a} t+\sum_{i=1}^{4} \delta_{i}\left(m_{a, t, r}\right)^{i}+\varepsilon_{a, r, t} .
\end{aligned}
$$


The dependent variable $h_{a, t, r}$ is the average HCE at age $a$ and time $t$ in the canton $r$ differentiated with respect to men and women (we suppressed the subscript for the gender). $\alpha_{1,0,1}$ is a constant for the first age group (0-5) of women in the initial year in the benchmark canton Aargau (reference group when all other dummy variables are set to zero). $d_{\text {sex }}$ is a dummy variable for the gender, which is assumed to be zero for women and one for men. The coefficient $\theta$ then measures the difference in HCE between men and women. $d_{r}$ are dummies for the cantons except for Aargau; $\kappa_{r}$ indicates the HCE differences to the benchmark canton. $d_{a}$ are dummies for the age classes and $\mu_{a}$ denotes the difference in HCE between age class $a$ and the first age class.

We address steepening first by using the growth rate of HCE for all people of age 50 or younger as the benchmark. The coefficient $\beta$ corresponds to this growth rate. The coefficients $\gamma_{a}, a=11,12, \ldots, 20$, then measure the difference to $\beta$ for the age groups older than 50 years. Secondly, we consider the change in the HCE age gradient for the people of age $50+$ by calculating $\gamma_{a+1}-\gamma_{a}$. Steepening is present if $\gamma_{a+1}-\gamma_{a}>0$, that is the growth rate of HCE in a given age group is larger than that in the next younger age group. This again is confined to the $50+$ age groups.

Finally, the effect of the mortality rate on HCE is captured by a polynomial function of power four (the corresponding coefficients represented by $\left.\delta_{i}\right)^{13}$ and $\varepsilon_{a, r, t}$ is the error term in the estimation.

The estimation results for Eq. (9), controlled for possible heteroskedasticity of the error term using the Huber-White estimator ${ }^{14}$ are presented in Table 4 . The constant indicates the logarithm of HCE in $2006 \mathrm{SFr}$. of the youngest female age group (girls aged 0-5) in Aargau in 1997. Transforming the constant (abstracting from the smearing factor) gives $693 \mathrm{SFr}$. Men on average incur 21.6 per cent lower HCE than women. The estimated respective differences in HCE between cantons $r 2, \ldots, r 20$ and the benchmark region Aargau follow the figures given in Table 2. The coefficients for the age group $(a 2, \ldots, a 20)$ show the well-known pattern with strongly rising HCE beyond age 51 . The age group $96+$ incurs 3.7 times $(\approx \exp (2.1676-0.8489))$ higher average HCE compared to the age group 46-50.

The coefficients for the effect of mortality are significant. The effect of mortality on HCE is positive as expected. Over all age classes, the mortality rate is 0.8 per cent and increases HCE by 0.81 per cent in 2006; beyond the age of 51 the average mortality rate is 2.6 per cent contributing an additional 27.20 per cent to HCE. ${ }^{15}$ These results indicate a strong positive impact of mortality on the age profile of $\mathrm{HCE}$ adding to the findings of the red herring literature. ${ }^{16}$

The estimated annual growth rate of real HCE between 1997 and 2006 is 3.23 per cent for the people of age 50 or younger. The coefficients $\gamma_{a}$ are significantly positive for most age groups indicating that the HCE growth rates in the age groups older than 51 years are larger than those for people of age 50 or younger. The

\footnotetext{
${ }^{13}$ We tested for this specification.

${ }^{14}$ See Wooldridge (2002).

${ }^{15}$ The effect of mortality is calculated by comparing the expected average HCE in 2006 with and without including the respective average value of mortality.

${ }^{16}$ See Zweifel et al. (1999).
} 
Table 4 Explaining $\ln (\mathrm{HCE})$ over time

\begin{tabular}{|c|c|c|c|c|c|}
\hline Variable & Coefficient & s.e. & Variable & Coefficient & s.e. \\
\hline Constant & $6.5409 * * * * *$ & 0.0140 & Sex & $-0.2432 * * * * *$ & 0.0064 \\
\hline Appenzell & $-0.2095 * * * * *$ & 0.0119 & Obwalden & $-0.1187 * * * * *$ & 0.0133 \\
\hline Baselland & $0.1406^{* * * * *}$ & 0.0106 & Schaffhausen & -0.0032 & 0.0112 \\
\hline Basel-Stadt & $0.2498 * * * * *$ & 0.0103 & Schwyz & $-0.0236 * * * *$ & 0.0111 \\
\hline Bern & $0.0441 * * * * *$ & 0.0102 & Solothurn & 0.0151 & 0.0101 \\
\hline Fribourg & $0.1376^{* * * * * *}$ & 0.0116 & St. Gallen & $-0.0662 * * * * *$ & 0.0102 \\
\hline Genève & $0.4845^{* * * * *}$ & 0.0106 & Ticino & 0.2286 & 0.0105 \\
\hline Glarus & $-0.0805^{* * * * *}$ & 0.0128 & Thurgau & 0.0161 & 0.0111 \\
\hline Graubünden & $-0.0827 * * * * *$ & 0.0108 & Uri & $-0.1486 * * * * *$ & 0.0117 \\
\hline Jura & $0.1963^{* * * * *}$ & 0.0131 & Vaud & $0.3211 * * * * *$ & 0.0112 \\
\hline Luzern & $-0.1027 * * * * *$ & 0.0107 & Valais & $0.0301 * * * * *$ & 0.0106 \\
\hline Neuchâtel & $0.2363 * * * * *$ & 0.0110 & Zug & $-0.0394 * * * * *$ & 0.0116 \\
\hline Nidwalden & $-0.1430 * * * * *$ & 0.0129 & Zürich & $0.1083^{* * * * *}$ & 0.0099 \\
\hline Age & & & Age & & \\
\hline $6-10$ & $-0.2763 * * * * *$ & 0.0157 & $56-60$ & $1.1866 * * * * *$ & 0.0153 \\
\hline $11-15$ & $-0.2441 * * * * *$ & 0.0128 & $61-65$ & $1.4152 * * * * *$ & 0.0186 \\
\hline $16-20$ & $0.0987 * * * * *$ & 0.0114 & $66-70$ & $1.4461 * * * * *$ & 0.0226 \\
\hline $21-25$ & $0.2973 * * * * *$ & 0.0136 & $71-75$ & $1.6532 * * * * *$ & 0.0295 \\
\hline $26-30$ & $0.4582 * * * * *$ & 0.0167 & $76-80$ & $1.6242 * * * * *$ & 0.0435 \\
\hline $31-35$ & $0.5707 * * * * *$ & 0.0157 & $81-85$ & $1.7179 * * * * *$ & 0.0672 \\
\hline $36-40$ & $0.5853 * * * * *$ & 0.0124 & $86-90$ & $1.6448 * * * * *$ & 0.0960 \\
\hline $41-45$ & $0.7278 * * * * *$ & 0.0112 & $91-95$ & $1.9345 * * * * *$ & 0.1170 \\
\hline $46-50$ & $0.8489 * * * * *$ & 0.0111 & $96+$ & $2.1676^{* * * * * *}$ & 0.1362 \\
\hline $51-55$ & $1.1196^{* * * * *}$ & 0.0141 & & & \\
\hline$t$ & $0.0323 * * * * *$ & 0.0010 & & & \\
\hline age $\cdot t$ & & & age $\cdot t$ & & \\
\hline $51-55 \cdot t$ & $-0.0045^{* * * * *}$ & 0.0015 & $76-80 \cdot t$ & $0.0168 * * * * *$ & 0.0019 \\
\hline $56-60 \cdot t$ & $0.0091 * * * * *$ & 0.0017 & $81-85 \cdot t$ & $0.0069 * * * * *$ & 0.0021 \\
\hline $61-65 \cdot t$ & $0.0023 * *$ & 0.0021 & $86-90 \cdot t$ & $0.0121 * * * * *$ & 0.0022 \\
\hline $66-70 \cdot t$ & $0.0148 * * * * *$ & 0.0023 & $91-95 \cdot t$ & $-0.0102 * * * * *$ & 0.0029 \\
\hline $71-75 \cdot t$ & $0.0077 * * * * *$ & 0.0021 & $96+\cdot t$ & $-0.0128 * * * * *$ & 0.0046 \\
\hline$m$ & $10.1661 * * * * *$ & 1.0694 & $m^{3}$ & $51.7701 * * * * *$ & 6.4451 \\
\hline$m^{2}$ & $-36.4680 * * * * *$ & 3.9354 & $m^{4}$ & $-24.2620 * * * * *$ & 3.6035 \\
\hline $\begin{array}{l}\text { Number of } \\
\text { observations }\end{array}$ & 10,000 & & $R^{2}$ & 0.974 & \\
\hline
\end{tabular}

$*, * *, * * *$ Significant at the $90,95,99 \%$ confidence levels, respectively.

differences in the growth rate are in the range 0.9 and 1.6 percentage points. For the age groups 51-55, 91-95 and 96+-year-olds, the coefficient is significantly negative, indicating that we can rule out that steepening occurs in these age classes.

A second test for steepening considers the change of the age-specific growth rate. The difference $\gamma_{a+1}-\gamma_{a}$ is positive four times and negative five times; except for the 
Table 5 Estimation results for $\ln (\mathrm{HCE})$ when the mortality rate is not included as an explanatory variable (the coefficients for the cantons are not presented)

\begin{tabular}{|c|c|c|c|c|c|}
\hline Variable & Coefficient & s.e. & Variable & Coefficient & s.e. \\
\hline Constant & $6.5317 * * *$ & 0.0136 & Sex & $-0.2013 * * *$ & 0.0035 \\
\hline Age & & & Age & & \\
\hline $6-10$ & $-0.2852 * * *$ & 0.0145 & $56-60$ & $1.2355 * * *$ & 0.0139 \\
\hline $11-15$ & $-0.2527 * * *$ & 0.0118 & $61-65$ & $1.4991 * * *$ & 0.0164 \\
\hline $16-20$ & $0.0931 * * *$ & 0.0109 & $66-70$ & $1.5864 * * *$ & 0.0183 \\
\hline $21-25$ & $0.2937 * * *$ & 0.0135 & $71-75$ & $1.8909 * * *$ & 0.0179 \\
\hline $26-30$ & $0.4544 * * *$ & 0.0169 & $76-80$ & $2.0119 * * *$ & 0.0161 \\
\hline $31-35$ & $0.5675^{* * *}$ & 0.0158 & $81-85$ & $2.3260 * * *$ & 0.0160 \\
\hline $36-40$ & $0.5841 * * *$ & 0.0122 & $86-90$ & $2.4952 * * *$ & 0.0152 \\
\hline $41-45$ & $0.7317 * * *$ & 0.0107 & $91-95$ & $2.8888 * * *$ & 0.0217 \\
\hline $46-50$ & $0.8607 * * *$ & 0.0104 & $96+$ & $3.1189 * * *$ & 0.0312 \\
\hline $51-55$ & $1.1466^{* * *}$ & 0.0134 & & & \\
\hline$t$ & $0.0320 * * *$ & 0.0010 & & & \\
\hline Age $\cdot t$ & & & Age $\cdot t$ & & \\
\hline $51-55 \cdot t$ & $-0.0049 * * *$ & 0.0016 & $76-80 \cdot t$ & $0.0083 * * *$ & 0.0022 \\
\hline $56-60 \cdot t$ & $0.0082 * * *$ & 0.0017 & $81-85 \cdot t$ & -0.0022 & 0.0020 \\
\hline $61-65 \cdot t$ & 0.0005 & 0.0022 & $86-90 \cdot t$ & $0.0044 * * *$ & 0.0019 \\
\hline $66-70 \cdot t$ & $0.0114 * * *$ & 0.0025 & $91-95 \cdot t$ & $-0.0116^{* * *}$ & 0.0028 \\
\hline $71-75 \cdot t$ & 0.0013 & 0.0025 & $96+\cdot t$ & $-0.0145^{* * *}$ & 0.0042 \\
\hline $\begin{array}{l}\text { Number of } \\
\text { observations }\end{array}$ & 10,000 & & $R^{2}$ & 0.9722 & \\
\hline
\end{tabular}

$*, * *, * *$ Significant at the $90,95,99 \%$ confidence levels, respectively.

oldest group, the difference is significant for all age groups according to an $F$-test. Hence, we cannot confirm steepening as a general pattern in the older age groups.

In the previous section, we argued that the change in the age-specific growth rate was intertwined with the change in the mortality rate. In order to test for the influence of the mortality rate, we re-estimated the equation but omitted the mortality rate. The results are presented in Table 5 .

As we expected from Eq. (5), the coefficients for $d_{a} t$ decrease when mortality is not included as an explanatory variable. For four age groups the coefficient remains significantly positive indicating steepening; but the effects are rather small. Not including mortality in the regression significantly increases the coefficient for the age dummies in old age. This again shows that mortality is an important factor for determining the age profile of HCE.

We also analysed a linear trend over time and confirmed the results of the logarithmic specification. Furthermore, when we captured age as a categorical variable and specified a polynomial function which we combined with time to test for steepening - similar to the third approach by Buchner and Wasem - the test outcome was negative. 
We estimated the equation separately for men and women, and found no qualitative difference with respect to steepening, although women's mortality had a stronger effect on their HCE age profile as compared to the men's.

Aggregating the ages above 51 years into one group and comparing its growth rate to that of the young, we found no steepening when mortality was not included in the regression. When we included it, steepening was present at the 90 per cent significance level. A comparison of the over-71-year-olds with the 0-70-year-olds in both specifications shows that no significant steepening effect occurred. Again, we cannot verify the Buchner-Wasem findings.

In the upper age classes, the number of observations is quite low, which can lead to outliers both in the HCE levels and the mortality rates. When we exclude observations with less than 100 persons, the lower growth rate in the oldest age group is no longer significant, but remains significant in the 90-95 age group.

The equation does not weight the cantonal per capita HCE at age $a$ with the respective population size, which may give small cantons too much weight. However, using total HCE and adding the population size as an independent variable does not change the results.

We observe not only differences in the level of cantonal per capita HCE, but also in the extent they change over time. Similarly, we may also have differences in the change of the age profile across cantons. Thus, we extended our estimation to include the following variables referring to the passage of time:

$$
t\left(\beta+\rho_{r} d_{r}+\sum_{r=2}^{25} d_{r} \sum_{a=11}^{20} \gamma_{a, r} d_{a}\right) .
$$

Here, $\beta+\rho_{r}$ is the average HCE growth rate for the people of age 50 or younger in canton $r . \beta+\rho_{r}$ will serve as the benchmark for the test of steepening. Using the estimated coefficients $\beta, \rho_{r}$ and $\gamma_{a, r}$ and their standard errors, we calculated the difference for the older age groups in the HCE growth rate and its significance. Table 6 presents the results.

The first column indicates large differences in the HCE growth rate for the population below 50 across the cantons. The largest growth rate (5.37 per cent) is observed for the small canton of Glarus in the center, while the even smaller canton of Jura in the northwest has the lowest annual growth rate ( 0.69 per cent). The correlation between the level and the baseline growth rate of $\mathrm{HCE}$ is negative $(r=-0.235)$, but is not significant.

In cantons where the per capita HCE growth rate for the young population is low, the coefficients for steepening tend to be positive (e.g. the cantons Jura and Fribourg). Similarly, in the cantons with a low level of HCE (see Table 2), the steepening coefficients are positive as well. By comparison, high-cost cantons such as Basel-Stadt and Geneva tend to have a lower growth rate in the old age groups compared to the baseline growth. In Zurich, the biggest canton, people of age 50 or younger experienced an average HCE growth rate. Only one older age group (76-80) incurred significantly higher HCE growth.

Steepening in the strict sense, that is, a general increase in the age gradient for people of age 51 or older, is not present in the data, as the difference in the coefficients 
Table 6 The difference in the HCE growth rate between the young $(0-50)$ and the older age groups $(51-55,56-60, \ldots, 96+)-$ regression results

\begin{tabular}{|c|c|c|c|c|c|c|c|c|c|c|c|}
\hline & $\begin{array}{c}t \\
(\%)\end{array}$ & $\begin{array}{c}51-55 \\
(\%)\end{array}$ & $\begin{array}{c}56-60 \\
(\%)\end{array}$ & $\begin{array}{c}61-65 \\
(\%)\end{array}$ & $\begin{array}{c}66-70 \\
(\%)\end{array}$ & $\begin{array}{c}71-75 \\
(\%)\end{array}$ & $\begin{array}{c}76-80 \\
(\%)\end{array}$ & $\begin{array}{c}81-85 \\
(\%)\end{array}$ & $\begin{array}{c}86-90 \\
(\%)\end{array}$ & $\begin{array}{c}91-95 \\
(\%)\end{array}$ & $\begin{array}{l}96+ \\
(\%)\end{array}$ \\
\hline Aargau & $4.08^{* * *}$ & -0.25 & $1.43^{* * *}$ & $1.03^{* * *}$ & $2.39 * * *$ & $1.44 * * *$ & $2.34 * * *$ & $0.46^{*}$ & $0.66^{* *}$ & $-1.89 * * *$ & $-1.66^{* * *}$ \\
\hline Appenzell & $4.48^{* * *}$ & -0.12 & 0.96 & 0.27 & 1.77 & 1.28 & $1.78 * * *$ & $-0.51^{*}$ & 0.17 & $-2.81 * * *$ & $-2.58 * * *$ \\
\hline Baselland & $3.55 * * *$ & $-1.50 * * *$ & 0.08 & $-0.63 * *$ & 1.12 & 0.29 & $1.36 * * *$ & 0.28 & 0.36 & $-3.28 * * *$ & $-4.68 * * *$ \\
\hline Basel-Stadt & $3.38 * * *$ & -0.77 & 0.40 & -0.76 & 0.40 & $-0.70 * *$ & 0.49 & $-0.26^{*}$ & 0.13 & $-3.04 * * *$ & $-3.09 * * *$ \\
\hline Bern & $4.54^{* * *}$ & -0.18 & $1.53^{* * *}$ & 1.00 & $2.63^{* * *}$ & $1.56^{* * *}$ & $2.52 * * *$ & $0.88^{* *}$ & $1.36^{* * *}$ & $-1.40 * * *$ & $-1.27 * * *$ \\
\hline Fribourg & $1.60 * * *$ & 0.19 & $1.79 * * *$ & 1.39 & $1.84 * * *$ & $1.53 * * *$ & $1.92 * * *$ & $1.42 * * *$ & $1.82 * * *$ & $1.56^{* *}$ & 0.81 \\
\hline Glarus & $5.37 * * *$ & $-1.78 * * *$ & $-0.54^{*}$ & $-1.92 * * *$ & -0.35 & $-1.31 * * *$ & $-0.66^{* *}$ & $-2.69 * * *$ & $-1.90 * * *$ & $-3.88 * * *$ & $-7.11 * * *$ \\
\hline Graubünden & $3.90^{* * *}$ & 0.06 & $1.97 * * *$ & $1.08^{* *}$ & $2.30^{* *}$ & $1.20^{* *}$ & $2.58 * * *$ & $0.84^{*}$ & $1.33^{* * *}$ & $-1.77 * * *$ & $-2.41 * * *$ \\
\hline Jura & $0.67 * * *$ & 0.01 & $1.83^{* * *}$ & $1.46^{* *}$ & $2.06^{* *}$ & $2.05^{* * *}$ & $2.90 * * *$ & $3.74^{* * *}$ & $4.52^{* * *}$ & $3.86^{* * *}$ & $3.41 * *$ \\
\hline Luzern & $3.35^{* * *}$ & 0.38 & $2.22 * * *$ & $1.72 * * *$ & $3.04 * * *$ & $2.52 * * *$ & $3.42^{* * *}$ & $2.87 * * *$ & $3.38 * * *$ & $1.04 *$ & 0.67 \\
\hline Neuchâtel & $2.63^{* * *}$ & 0.12 & $1.00^{* *}$ & 0.39 & $1.46^{* *}$ & 0.53 & $1.91^{* * *}$ & $1.07^{*}$ & $2.38^{* * *}$ & 0.82 & $2.02 * * *$ \\
\hline Nidwalden & $2.65^{* * *}$ & 0.05 & $1.84^{* * *}$ & $1.38 * *$ & $2.00 * * *$ & $1.71 * * *$ & $1.65^{* * *}$ & $1.04 *$ & $2.12^{* * *}$ & 0.80 & 0.82 \\
\hline Obwalden & $2.51 * * *$ & -0.52 & $1.64 * * *$ & $1.18 * *$ & $2.17 * * *$ & $2.35 * * *$ & $2.74 * * *$ & $2.01 * * *$ & $3.28 * * *$ & $2.02 * * *$ & -0.44 \\
\hline Schaffhausen & $3.54 * * *$ & -0.21 & $1.90 * * *$ & 0.88 & $2.27 * * *$ & $1.00 * *$ & $2.40 * * *$ & 0.54 & 0.87 & $-1.72 * * *$ & 0.13 \\
\hline Solothurn & $3.93^{* * *}$ & -0.51 & $1.34^{* * *}$ & 0.58 & $1.96^{* * *}$ & $1.29 * *$ & $2.06^{* * *}$ & $0.94 * *$ & $1.20 * *$ & $-1.95^{* * *}$ & $-2.18 * * *$ \\
\hline St. Gallen & $4.49^{* * *}$ & -0.47 & 0.76 & -0.02 & $1.10^{*}$ & 0.28 & $0.97 * *$ & $-0.49 * *$ & 0.24 & $-1.85^{* * *}$ & $-1.57 * * *$ \\
\hline Ticino & $2.47 * * *$ & -0.20 & $1.74 * * *$ & $1.25 * *$ & $2.82 * * *$ & $2.10 * * *$ & $3.18 * * *$ & $2.12^{* * *}$ & $1.54 * * *$ & $-1.72 * * *$ & $-3.57 * * *$ \\
\hline Thurgau & $2.83^{* * *}$ & -0.38 & $1.33^{* *}$ & 0.48 & $1.77 * *$ & $1.19^{*}$ & $1.92 * * *$ & 0.28 & 0.33 & $-2.32 * * *$ & $-2.37 * * *$ \\
\hline Uri & $2.76^{* * *}$ & 0.17 & $1.80^{* * *}$ & $1.37 * *$ & $2.74 * * *$ & $1.95^{* * *}$ & $3.26^{* * *}$ & $2.54 * * *$ & $2.62^{* * *}$ & 0.04 & $2.06^{* *}$ \\
\hline Vaud & $2.56^{* * *}$ & $-1.04 * * *$ & 0.70 & 0.10 & $1.59 * * *$ & 0.77 & $1.84 * * *$ & 0.79 & $1.42 * * *$ & $-1.27 * * *$ & $-0.75^{*}$ \\
\hline Valais & $2.69^{* * *}$ & -0.26 & $1.57 * * *$ & 0.97 & $1.41^{* *}$ & 0.86 & $1.83^{* * *}$ & 1.56 & $2.12^{* * *}$ & 0.09 & 0.18 \\
\hline Zug & $2.87 * * *$ & -0.33 & $1.50^{* * *}$ & $1.13 * *$ & $2.73^{* * *}$ & $1.80^{* * *}$ & $3.20 * * *$ & $3.22 * * *$ & $2.91 * * *$ & $1.26^{* * *}$ & 1.09 \\
\hline Zürich & $3.48 * * *$ & $-1.50 * * *$ & -0.07 & $-0.90 * * *$ & 0.90 & -0.13 & $1.25^{* * *}$ & 0.13 & $0.98 * *$ & -1.49 & $-0.95^{* *}$ \\
\hline
\end{tabular}

$*, * *, * * *$ Significant at the $90,95,99 \%$ confidence level. 
$\gamma_{a+1, r}-\gamma_{a, r}$ shows no robust pattern. By and large, the cantonal results do not support the steepening claim either.

This holds for the Swiss social health insurance system in the time period 1997-2006. In qualitative terms it should also apply to other systems facing rising HCE and changes in the demographic structure of the population. Possible limitations of the finding concern are the rather small number of observations in some age groups of the cantons and the lack of supply-side factors in the econometric equations. The latter, however, is at least indirectly captured by the cantons' dummies.

\section{Steepening in components of HCE?}

Table 7 presents the regression results of the equation with and without mortality rates for the components of $\mathrm{HCE}$. With regard to the impact of mortality on $\mathrm{HCE}$, a significant difference between components of acute care and long-term care arises. Whereas mortality has a major effect on the age profile of acute care, its impact on long-term care is only minor. It is then not surprising that age has a marked effect on HCE (see the sizeable coefficient of the age dummies for home and NHC in Table 7). This is similar to the findings of Werblow et al., ${ }^{17}$ who report significant age effects for long-term care when controlling for proximity to death.

Home care expenditures for people of age 50 or younger increased by 10.92 per cent per year over the 10 years in question. The growth rate is lower for the older age groups. Steepening is not present at all in the demand for $\mathrm{HC}$, despite the observation in Table 3 that the ratio in per capita expenditure between the old and the young increased between 1997 and 2006. It appears that a strong stochastic element impacts on the $\mathrm{HC}$ component of young people.

Nursing home expenditure is different. From 1997 onwards, the under-51-year-olds decreased their average expenditure at an annual rate of 26 per cent. With the exception of the 51-55 age group, all over-51-years-olds experienced a positive growth in average nursing home expenditure. Still, steepening in the strict sense (an increase in the age gradients) again does not exist for old age groups.

Turning to acute care, a differentiated pattern regarding steepening arises. All outpatient care components (AC, drugs, HOP and other) mostly show a positive sign for $\gamma_{a}$, except for the two oldest age groups. The average growth rate of expenditure for the young people substantially differs between components of outpatient care. It is lowest in AC (1.86 per cent), followed by sundry services (2.49 per cent), drugs (3.08 per cent) and HOP (5.87 per cent). The difference in growth for older age groups is more or less constant across components. A robust pattern of increasing age coefficients cannot be found.

Steepening can be ruled out for HIP, where all $\gamma_{a}$ are significantly negative. The baseline growth rate is 3.92 per cent, comparable to the overall baseline growth of 3.23 per cent. This result is in sharp contrast to Buchner and Wasem, ${ }^{18}$ who found substantial steepening for inpatient care in all specifications.

\footnotetext{
${ }^{17}$ Werblow et al. (2007).

${ }^{18}$ Buchner and Wasem (2006).
} 
Table 7 Steepening in the components of HCE - regression results

\begin{tabular}{|c|c|c|c|c|c|c|c|c|c|c|c|c|c|c|}
\hline & \multicolumn{2}{|c|}{$\begin{array}{c}\text { Ambulatory } \\
\text { care }\end{array}$} & \multicolumn{2}{|c|}{ Drugs } & \multicolumn{2}{|c|}{$\begin{array}{c}\text { Hospital } \\
\text { inpatient care }\end{array}$} & \multicolumn{2}{|c|}{$\begin{array}{c}\text { Hospital } \\
\text { outpatient care }\end{array}$} & \multicolumn{2}{|c|}{ Home care } & \multicolumn{2}{|c|}{$\begin{array}{l}\text { Nursing } \\
\text { home care }\end{array}$} & \multicolumn{2}{|c|}{ Other } \\
\hline & $\begin{array}{c}\text { With } \\
m\end{array}$ & $\begin{array}{c}\text { Without } \\
m\end{array}$ & $\begin{array}{c}\text { With } \\
m\end{array}$ & $\begin{array}{c}\text { Without } \\
m\end{array}$ & $\begin{array}{c}\text { With } \\
m\end{array}$ & $\begin{array}{c}\text { Without } \\
m\end{array}$ & $\begin{array}{c}\text { With } \\
m\end{array}$ & $\begin{array}{c}\text { Without } \\
m\end{array}$ & $\begin{array}{c}\text { With } \\
m\end{array}$ & $\begin{array}{c}\text { Without } \\
m\end{array}$ & $\begin{array}{c}\text { With } \\
m\end{array}$ & $\begin{array}{c}\text { Without } \\
m\end{array}$ & $\begin{array}{c}\text { With } \\
m\end{array}$ & $\begin{array}{c}\text { Without } \\
m\end{array}$ \\
\hline $\mathrm{a} 2$ & $-0.4131^{* * *}$ & $-0.4208 * * *$ & $-0.3065^{* * *}$ & $-0.3092 * * *$ & $-0.6175^{* * *}$ & $-0.6303 * * *$ & -0.0252 & $-0.0389 *$ & $-0.6585^{* * *}$ & $-0.6584 * * *$ & -0.0221 & -0.0170 & $0.4304 * * *$ & $0.4200 * * *$ \\
\hline a3 & $-0.4930^{* * *}$ & $-0.5004 * * *$ & $-0.3207 * * *$ & $-0.3233 * * *$ & $-0.3314 * * *$ & $-0.3438 * * *$ & -0.0078 & -0.0210 & -0.1380 & -0.1380 & $1.2725 * * *$ & $* \quad 1.2774 * * *$ & $0.6622 * * *$ & $0.6521 * * *$ \\
\hline a4 & $-0.2930^{* * *}$ & $-0.2978 * * *$ & $0.1120^{* * *}$ & $0.1103^{* * *}$ & $0.4634 * * *$ & $0.4552 * * *$ & $0.1429 * * *$ & $0.1342 * * *$ & $0.9395^{* * *}$ & $=0.9395 * * *$ & $2.4444 * * *$ & * $\quad 2.4476 * * *$ & $0.9186^{* * *}$ & $0.9120 * * *$ \\
\hline a5 & $-0.1857^{* * *}$ & $-0.1888 * * *$ & $0.3160^{* * *}$ & $0.3149^{* * *}$ & $0.7926^{* * *}$ & $0.7874 * * *$ & $0.3716^{* * *}$ & $0.3661 * * *$ & $1.8547^{* * *}$ & $1.8547 * * *$ & $3.4797 * * *$ & $* \quad 3.4818 * * *$ & $1.0520^{* * *}$ & $1.0478 * * *$ \\
\hline a6 & $-0.0475^{* * *}$ & $-0.0508 * * *$ & $0.4827 * * *$ & $0.4816^{* * *}$ & $0.9871 * * *$ & $0.9816 * * *$ & $0.5583^{* * *}$ & $0.5525 * * *$ & $2.4203^{* * *}$ & $2.4203 * * *$ & $4.1902 * * *$ & $* \quad 4.1923 * * *$ & $1.1443^{* * *}$ & $1.1399 * * *$ \\
\hline a7 & $0.0564 * * *$ & $0.0536 * * *$ & $0.6793 * * *$ & $0.6784 * * *$ & $1.0540^{* * *}$ & $1.0492 * * *$ & $0.6800^{* * *}$ & $0.6749 * * *$ & $2.7634 * * *$ & $=2.7634 * * *$ & $4.9682 * * *$ & $* \quad 4.9701 * * *$ & $1.2372 * * *$ & $1.2334 * * *$ \\
\hline a8 & $0.0865 * * *$ & $0.0855 * * *$ & $0.8082 * * *$ & $0.8079 * * *$ & $0.9690 * * *$ & $0.9672 * * *$ & $0.7194 * * *$ & $0.7175^{* * *}$ & $3.1072 * * *$ & $=3.1072 * * *$ & $5.6400 * * *$ & $* \quad 5.6407 * * *$ & $1.2199 * * *$ & $1.2185^{* * *}$ \\
\hline a9 & $0.2196^{* * *}$ & $0.2230 * * *$ & $1.0452 * * *$ & $1.0463 * * *$ & $1.0784 * * *$ & $1.0840 * * *$ & $0.8275^{* * *}$ & $0.8334 * * *$ & $3.7430 * * *$ & $\quad 3.7430 * * *$ & $6.6075^{* * *}$ & $* \quad 6.6053^{* * *}$ & $1.3189^{* * *}$ & $1.3235 * * *$ \\
\hline a 10 & $0.3027^{* * *}$ & $0.3129 * * *$ & $1.2386^{* * *}$ & $1.2421^{* * *}$ & $1.2128^{* * *}$ & $1.2300 * * *$ & $0.9214 * * *$ & $0.9397 * * *$ & $4.0664 * * *$ & $=4.0664 * * *$ & $7.0653^{* * *}$ & $* \quad 7.0585^{* * *}$ & $1.4023^{* * *}$ & $1.4162 * * *$ \\
\hline a11 & $0.4964 * * *$ & $0.5198 * * *$ & $1.5642 * * *$ & $1.5723 * * *$ & $1.5598 * * *$ & $1.5989 * * *$ & $1.1687^{* * *}$ & $1.2103 * * *$ & $4.8239 * * *$ & $4.8239 * * *$ & $6.7889 * * *$ & $* \quad 6.7733^{* * *}$ & $1.6284^{* * *}$ & $1.6602 * * *$ \\
\hline a12 & $0.4946^{* * *}$ & $0.5370 * * *$ & $1.6928^{* * *}$ & $1.7076^{* * *}$ & $1.6865^{* * *}$ & $1.7575 * * *$ & $1.1968^{* * *}$ & $1.2725 * * *$ & 5.2093 & $5.2095 * * *$ & $7.3049 * * *$ & * $\quad 7.2765^{* * *}$ & $1.5950 * * *$ & $1.6529 * * *$ \\
\hline a13 & $0.6697 * * *$ & $0.7424 * * *$ & $1.9760^{* * *}$ & $2.0014 * * *$ & $1.9753^{* * *}$ & $2.0975 * * *$ & $1.3444^{* * *}$ & $1.4744 * * *$ & $5.7767 * * *$ & $5.7772 * * *$ & $7.7839 * * *$ & $* \quad 7.7348 * * *$ & $1.7210^{* * *}$ & $1.8206^{* * *}$ \\
\hline a15 & $0.7287^{* * *}$ & $0.9372 * * *$ & $2.2262 * * *$ & $2.3002 * * *$ & $2.3349 * * *$ & $2.6873 * * *$ & $1.3559 * * *$ & $1.7293 * * *$ & $7.0653^{* * *}$ & $=7.0705 * * *$ & $9.5480 * * *$ & $* \quad 9.4031 * * *$ & $1.6601 * * *$ & $1.9485 * * *$ \\
\hline a16 & $0.5944 * * *$ & $0.9387 * * *$ & $2.1962 * * *$ & 2.3203 & $2.2744 * * *$ & $2.8597 * * *$ & $0.9775^{* * *}$ & $1.5951 * * *$ & $7.6423 * * *$ & $=7.6575 * * *$ & $10.4639 * * *$ & * $10.2174 * * *$ & $1.3885^{* * *}$ & $1.8696 * * *$ \\
\hline a17 & $0.4993^{* * *}$ & $1.0527 * * *$ & $2.2481 * * *$ & $2.4539 * * *$ & $2.2086^{* * *}$ & $3.1613 * * *$ & $0.6130 * * *$ & $1.6103 * * *$ & $8.3422 * * *$ & $8.3872 * * *$ & $11.5286^{* * *}$ & * $11.1090 * * *$ & $1.1874 * * *$ & $1.9760 * * *$ \\
\hline a18 & 0.1446 & $0.9571 * * *$ & $2.0430 * * *$ & $2.3618^{* * *}$ & $1.8249 * * *$ & $3.2560 * * *$ & 0.0128 & $1.4913 * * *$ & $8.6546^{* * *}$ & $=8.7747 * * *$ & $12.4120 * * *$ & * $11.7342 * * *$ & $0.7984 * * *$ & $1.9919 * * *$ \\
\hline a19 & 0.0361 & $1.0308 * * *$ & $1.9969^{* * *}$ & $2.4190 * * *$ & $1.5772 * * *$ & $3.3935 * * *$ & -0.2698 & $1.5748 * * *$ & $8.9723 * * *$ & $9.2123 * * *$ & $13.4508^{* * *}$ & * $12.5157 * * *$ & $0.6324 * *$ & $2.1314 * * *$ \\
\hline a20 & -0.1285 & $0.9561 * * *$ & $1.7604^{* * *}$ & $2.2643 * * *$ & $1.2605^{* *}$ & $3.2471 * * *$ & $-0.7841^{*}$ & $1.1488 * * *$ & $8.9047^{* * *}$ & $=9.1657 * * *$ & $13.8533^{* * *}$ & * $12.9177 * * *$ & 0.6084 & $2.0362 * * *$ \\
\hline & $0.0186^{* * *}$ & $0.0184 * * *$ & $0.0308^{* * *}$ & $0.0307 * * *$ & $0.0392 * * *$ & $0.0388 * * *$ & $0.0587 * * *$ & $0.0583 * * *$ & $0.1092 * * *$ & $0.1092 * * *$ & $-0.2641 * * *$ & $* 0.2640 * * *$ & $0.0252 * * *$ & $0.0249 * * *$ \\
\hline
\end{tabular}


Table 7 Continued

\begin{tabular}{|c|c|c|c|c|c|c|c|c|c|c|c|c|c|c|}
\hline & \multicolumn{2}{|c|}{$\begin{array}{c}\text { Ambulatory } \\
\text { care }\end{array}$} & \multicolumn{2}{|c|}{ Drugs } & \multicolumn{2}{|c|}{$\begin{array}{c}\text { Hospital } \\
\text { inpatient care }\end{array}$} & \multicolumn{2}{|c|}{$\begin{array}{c}\text { Hospital } \\
\text { outpatient care }\end{array}$} & \multicolumn{2}{|c|}{ Home care } & \multicolumn{2}{|c|}{$\begin{array}{l}\text { Nursing } \\
\text { home care }\end{array}$} & \multicolumn{2}{|c|}{ Other } \\
\hline & $\begin{array}{c}\text { With } \\
m\end{array}$ & $\begin{array}{c}\text { Without } \\
m\end{array}$ & $\begin{array}{c}\text { With } \\
m\end{array}$ & $\begin{array}{c}\text { Without } \\
m\end{array}$ & $\begin{array}{c}\text { With } \\
m\end{array}$ & $\begin{array}{c}\text { Without } \\
m\end{array}$ & $\begin{array}{c}\text { With } \\
m\end{array}$ & $\begin{array}{c}\text { Without } \\
m\end{array}$ & $\begin{array}{c}\text { With } \\
m\end{array}$ & $\begin{array}{c}\text { Without } \\
m\end{array}$ & $\begin{array}{c}\text { With } \\
m\end{array}$ & $\begin{array}{c}\text { Without } \\
m\end{array}$ & $\begin{array}{c}\text { With } \\
m\end{array}$ & $\begin{array}{c}\text { Without } \\
m\end{array}$ \\
\hline at11 & -0.0018 & -0.0022 & 0.0030 & 0.0029 & $-0.0161 * * *$ & $*-0.0166^{* * *}$ & -0.0028 & -0.0034 & -0.0272 & -0.0272 & $0.2314 * * *$ & $0.2316^{* * *}$ & $-0.0128 * * *$ & $-0.0132 * * *$ \\
\hline at12 & $0.0125^{* * *}$ & $0.0118^{* * *}$ & $0.0167 * * *$ & $0.0165^{* * *}$ & $-0.0081^{* *}$ & $-0.0093^{* * *}$ & $\quad 0.0136^{* * *}$ & $0.0122 * * *$ & -0.0039 & -0.0039 & $0.2612 * * *$ & $0.2617 * * *$ & $0.0053^{* *}$ & $0.0043^{* *}$ \\
\hline at13 & $0.0054 * * *$ & $0.0039 * *$ & $0.0076 * * *$ & $0.0071 * * *$ & $-0.0186^{* * *}$ & $*-0.0212^{* * *}$ & $0.0139 * * *$ & $0.0111 * * *$ & -0.0204 & -0.0204 & $0.3155 * * *$ & $0.3166^{* * *}$ & $0.0008 * *$ & -0.0014 \\
\hline at14 & $0.0215^{* * *}$ & $0.0185^{* * *}$ & $0.0219 * * *$ & $0.0208 * * *$ & $-0.0086^{* *}$ & $-0.0138^{* * *}$ & $0.0201 * * *$ & $=0.0147 * * *$ & $-0.0253^{*}$ & $-0.0254^{*}$ & $0.3184 * * *$ & $0.3206 * * *$ & $0.0206^{* * *}$ & $0.0163^{* * *}$ \\
\hline at15 & $0.0156^{* * *}$ & $0.0100 * * *$ & $0.0147 * * *$ & $0.0127 * * *$ & $-0.0168^{* * *}$ & $*-0.0264^{* * *}$ & $0.0248 * * *$ & $0.0146^{* * *}$ & $-0.0474 * * *$ & $* 0.0476^{* * *}$ & $0.2918 * * *$ & $0.2959 * * *$ & $0.0104 * * *$ & $0.0024^{* *}$ \\
\hline at16 & $0.0253^{* * *}$ & $0.0175^{* * *}$ & $0.0242 * * *$ & $0.0212 * * *$ & -0.0072 & $-0.0207^{* * *}$ & $0.0445 * * *$ & $=0.0304 * * *$ & $-0.0374 * * *$ & $* 0.0380^{* * *}$ & $0.2963^{* * *}$ & $0.3023^{* * *}$ & $0.0260 * * *$ & $0.0148^{* * *}$ \\
\hline at17 & $0.0167 * * *$ & $0.0078 * * *$ & $0.0191 * * *$ & $0.0155^{* * *}$ & $-0.0202^{* * *}$ & $*-0.0360^{* * *}$ & $0.0243 * * *$ & $0.0080 *$ & $-0.0382 * *$ & $-0.0398 * * *$ & $0.2981 * * *$ & $0.3058 * * *$ & $0.0148 * * *$ & $0.0015^{* *}$ \\
\hline at18 & $0.0196^{* * *}$ & $0.0105 * * *$ & $0.0271 * * *$ & $0.0228 * * *$ & $-0.0203^{* * *}$ & $*-0.0377 * * *$ & 0.0010 & $-0.0162 * * *$ & -0.0227 & $-0.0263^{*}$ & $0.3111^{* * *}$ & $0.3213^{* * *}$ & $0.0038 * *$ & $-0.0110^{*}$ \\
\hline at19 & -0.0019 & -0.0068 & $0.0146 * * *$ & $0.0113 * * *$ & $-0.0413^{* * *}$ & * $-0.0528^{* * *}$ & $*-0.0574 * * *$ & $-0.0680 * * *$ & $-0.0378 * *$ & $-0.0422^{* * *}$ & $0.2925 * * *$ & $0.3008 * * *$ & $-0.0454 * * *$ & $-0.0536^{* * *}$ \\
\hline at 20 & -0.0018 & -0.0090 & $0.0211^{* * *}$ & $0.0149 * *$ & $-0.0525^{* * *}$ & $*-0.0639$ *** & $-0.0607 * * *$ & $-0.0647 * * *$ & -0.0255 & -0.0250 & $0.3027 * * *$ & $0.2991 * * *$ & $-0.0680 * * *$ & $-0.0605^{* * *}$ \\
\hline$m$ & $8.7602 * * *$ & & $3.0309^{* * *}$ & & $14.6653^{* * *}$ & & $15.6421 * * *$ & & -0.0365 & & $-5.7997^{*}$ & & $11.9167 * * *$ & \\
\hline$m^{2}$ & $-26.6948^{* * *}$ & & -6.8636 & & $-40.5014^{* * *}$ & & $-46.4707 * * *$ & & 8.0112 & & 8.8592 & & $-30.0595^{* *}$ & \\
\hline$m^{3}$ & $34.8057 * * *$ & & 6.3887 & & $49.9276^{* *}$ & & $62.4522^{* *}$ & & -19.1895 & & -2.7397 & & $29.8424 * *$ & \\
\hline$m^{4}$ & $-15.1688 * * *$ & & -1.3148 & & $-21.6636^{* *}$ & & $-30.7609^{*}$ & & 11.3473 & & -0.0875 & & -11.4279 & \\
\hline$R^{2}$ & 0.8900 & 0.883 & 0.9730 & 0.973 & 0.9110 & 0.906 & 0.7720 & 0.759 & 0.8 & 0.8 & 0.828 & 0.828 & 0.715 & 0.72 \\
\hline
\end{tabular}

$*, * *, * * *$ Significant at the $90,95,99 \%$ confidence level. 


\section{Conclusion}

If per capita health care expenditure (HCE) of the elderly grows faster than that of younger people, the age profile of per capita HCE becomes increasingly steeper. More precisely, steepening of the expenditure profile means that the growth rate of HCE is higher at old ages, possibly with an accentuation at very old age.

This paper addresses steepening, analysing Swiss social health insurance data in the 26 cantons over the time period from 1997 to 2006. The study incorporates mortality rates, a variable that has a marked impact on the age profile of HCE. At the aggregate national level, we find an average real growth rate of 3.23 per cent in per capita HCE of the population under 50 . Older age groups experience a slightly higher growth rate. For the very old, of age 91 or older, the growth rate is significantly lower. Although we find higher growth rates for some of the older age groups, a steepening of the age profile in the strict sense of a generally increasing growth rate of HCE in old age cannot be observed. For the very old, we even find an anti-steepening effect. These results, by and large, are confirmed at the cantonal level.

A decomposition of HCE reveals the following effects: for hospital inpatient care (HIP) and home care (HC), growth rates for older age groups are significantly lower than for the people of age 50 or younger. For nursing home care (NHC), ambulatory care (AC), hospital outpatient care (HOP) and prescription drugs, growth is higher in old age. However, a robust pattern of increasing HCE growth rates in old age over time cannot be detected. In particular, for the very old, an anti-steepening effect arises in all components of health care.

In summary, our results for the Swiss cantons provide no evidence for relevant steepening effects of age profiles for either total, or the components of, HCE over time. While this is good news from the perspective of the effect of population ageing on health care cost, pay-as-you-go financed health insurance systems will still come under marked pressure when the relative number between the young and the old shrinks during the demographic transition. ${ }^{19}$

\section{References}

Barros, P.P. (1998) 'The black box of health care expenditure growth determinants', Health Economics 7 : 533-544.

Breyer, F. and Felder, S. (2005) 'Life expectancy and health care expenditures in the 21st century: A new calculation for Germany using the costs of dying', Health Policy 75: 178-186.

Buchner, F. and Wasem, J. (2006) "'Steeping” of health expenditure profiles', The Geneva Papers on Risk and Insurance - Issues and Practice 31: 581-599.

Cheung, S.L.K. and Robine, J.M. (2007) 'Increase in common longevity and the compression of mortality: The case of Japan', Population Studies 61: 85-97.

Fries, J.F. (1980) 'Aging, natural death and the compression of morbidity', The New England Journal of Medicine 303: 130-135.

Fries, J.F. (2005) 'The compression of morbidity', The Milbank Quarterly 83: 801-823.

Gujarati, D.N. (2000) Basic Econometrics, New York: McGraw-Hill.

Hartwig, J. (2008) 'What drives health care expenditure? - Baumol's model of "unbalanced growth" revisited', Journal of Health Economics 27: 603-623.

\footnotetext{
${ }^{19}$ For example, Breyer and Felder (2005).
} 
OECD (2007) OECD Health Data 2007, Paris: OECD.

Schneider, E.L. and Guralnik, J.M. (1990) 'The aging of America: Impact on health care costs', Journal of the American Medical Association 263: 2335-2340.

Seshamani, M. and Gray, A. (2002) 'The impact of ageing on expenditures in the National Health Service', Age and Ageing 31: 287-294.

Werblow, A., Felder, S. and Zweifel., P. (2007) 'Population ageing and health care expenditure: A school of "red herrings"?' Health Economics 16: 1109-1127.

Wooldridge, J.M. (2002) Econometric Analysis of Cross Section and Panel Data, Cambridge, MA: MIT-Press.

Zweifel, P., Felder, S. and Meier, M. (1999) 'Ageing of population and health care expenditure: A red herring?' Health Economics 8: 485-496.

\section{About the Authors}

Stefan Felder was born in 1960 in Sursee, Switzerland. He was a student of Economics and Sociology. He received his diploma in 1985. He completed his $\mathrm{PhD}$ in Economics in 1989 and Habilitation in 1995 from the University of Bern. In 1990/92 he was a visiting scholar at the University of Western Ontario, in 1992/96 a senior economist at the University of Zurich, in 1993/95 a lecturer at the University of Fribourg and in 1997-2008 he worked as a professor of Health Economics, University of Magdeburg, Germany. Since July 2008, he has been working as a professor of Economics at the Duisburg-Essen University, Germany. His research fields are health economics and public economics.

Andreas Werblow was born in 1965. He studied Economics at the Technical University of Dresden. He received his diploma in 1998 and completed his PhD in Economics in 2004 from the University of Magdeburg. In 1998, he worked as a scientific economist at the Technical University of Dresden. From 1999 to 2005, he worked as a scientific economist at the Institute of Social Medicine and Health Economics, Magdeburg. Since 2005, he has been working as a freelancer in Health Economics and since 2006 as a senior economist at the Department of Economics, TU Dresden. 